\title{
Pesquisa, tecnologia e competitividade na agropecuária brasileira
}

\section{IVALO GEHLEN}

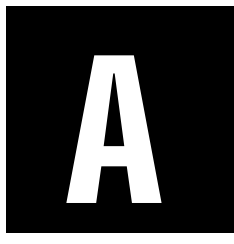

s transformações estruturais que ocorrem na agropecuária brasileira estão em interface com o desenvolvimento científico e tecnológico voltado para o setor. A constatação de risco de reprodutibilidade social, econômica, política e cultural do setor diante dos impactos decorrentes do processo produtivo e agroindustrial impõe permanente investimento em recursos humanos, em infraestrutura e em financiamento de pesquisas e experimentos. Impõe-se também um permanente processo de recomposição desses recursose de seleção de prioridades. A busca de consolidação hegemônica de um novo referencial em Ciência e Tecnologia Agropecuária ( $\&$ \&A) apresenta poucos consensos. U ma das possibilidades de construir consensos é o da noção de competitividade como meta das transformações e do desenvolvimento no setor. Tal consensualidade converte em natural a disputa entre diferentes e entre iguais pelo mesmo espaço, pela mesma atividade, pelo mesmo produto, e reintroduz a centralidade do trabalho, porém vinculada à necessidade de eficiência competitiva. Essa "nova" centralidade do trabalho abriga-se na chamada flexibilização, em nome da qual se transferem responsabilidades- pelo sucesso ou insucesso - para a esfera privada ou individual, perpetuando e, em muitos casos, acentuando as diferenças de oportunidades ${ }^{1}$ decorrentes das condiçõese do lugar de cada um no contexto.

\footnotetext{
* Professor do Departamento de Sociologia e dos Programas de Pós-Graduação de Sociologia, de Desenvolvimento Rural e de Agronegócios da UFRGS. ivaldo@ vortex.ufrgs.br

1 A respeito das diferenças nas oportunidades de disputa de interesses na sociedade contemporânea ver Dahrendorf, 1992.
} 
0 progresso técnico ${ }^{2}$, (re)conceituado como desenvolvimento, reverteu uma tradição milenar através da imposição da produtividade do trabalho, mensurada pelo tempo, como referência de cidadania moderna. No entanto o processo de concentração e acumulação da riqueza (exploração do trabalho), característica do moderno, continua e tende a ampliarse nas últimas décadas, no bojo do que se convencionou chamar de globalização de mercado. Em ciência e tecnologia, isso também ocorre. Dados difundidos pelo Programa das Nações Unidas para o Desenvolvimento em recente relatório (PNUD, 1999) revelam que os países desenvolvidos concentram ou são depositários de $95 \%$ das patentes concedidas, investem $84 \%$ de todos os recursos em pesquisa e produzem e consomem $86 \%$ dos produtos. Como os demais países que estão fora desse grupo, o Brasil prioriza a adoção de conhecimentos e tecnologias desses países em formatos de "pacotes" ${ }^{3}$. Tais pacotes, em geral, são implantados de forma forçada, pois não só os ambientes naturais são diferentes, como as tradições culturais e as formas de organização da sociedade e da produção. Por isso, para Maia:

Em alguns casos, como o do setor agrícola, os ambientes naturais são distintos e podem ter reações desconhecidas às técnicas utilizadas. A ciência e a tecnologia são hoje instrumentos indispensáveis para o sonho de desenvolvimento ideal que construa qualquer país, considerando suas potencialidades para oferecerem alternativas aos pad rões de produção e consumo estabelecidos (...) N esse contexto, está colocada a necessidade de se estabelecer uma política nacional de ciência e tecnologia voltada para a conquista da sustentabilidade, priorizando a eliminação da exclusão social e o uso sustentável dos recursos naturais (Maia, 2000, p. 371).

2 Sobre o chamado Progresso Técnico ver Graziano da Silva, 1981 e 1988.

3 Sobre o que é e o conteúdo do pacote tecnológico modernizador para o desenvolvimento da agropecuária brasileira, ver Aguiar, R.C. 1986. 
No período medieval, a Europa avançou na formulação do conceito de igualdade social, marcado pelo cristianismo, apesar de na prática persistir a estrutura social de dominação e desigualdade social. A estagnação tecnológica, porém, perdurou enquanto persistiu a noção grega de ciência como "saber teórico" ou então, a realidade com o espírito como ela é, permanece válida até hoje. Porém essa realidade "teórica" existe, e as pessoas esbarram com elas como objetos da ciência, mas também para ser transformada (Vargas, 1985), e esta é tarefa de quem tem o saber técnico, prático. Porém, segundo esse autor, entre a essência vista pelo espírito e a prática do técnico opera-se uma "modelagem" conduzida pela vontade humana, que entrelaça o saber teórico e o prático. A atitude de quem faz tecnologia é a combinação das duas (Vargas, 1985, p. 21). A superação da dicotomia "teórico - prático" pelo "saber moderno" foi condição necessária para o desenvolvimento de tecnologias e, estas, necessárias para a Revolução Industrial. Enquanto a Revolução Industrial não "chegou", o tempo livre continuou abundante e, eventualmente, esse tempo convertido em ócio poderia ser usado para pensar, reunir pessoas para trocar idéias, estudar, organizar lutas, sendo imperativo o controle social desse tempo através de feriados religiosos e atividades coletivas. A ascensão da burguesia politizou o conceito de igualdade e universalizou o trabalho como condição de cidadania política. A nova ideologia justificaria a exploração pelo trabalho como regenerador dos males, dignificador do ser humano, enfim, libertador. Neste sentido, atribuindo um valor positivo ao trabalho.

Transpondo para a agricultura, constata-se uma reversão de uma milenar tradição na relação tempo - trabalho, pela imposição do trabalho produtivo de mercadoria como referência valorativa de cidadania moderna. A lógica da produtividade (relação ideal entre trabalho-tecnologia-produção mensurada pelo tempo) desestruturou os saberes tradicionais, acumulados por gerações seguidas. 0 simpactos deste processo foram profundos, indeléveis e diferenciados, redefinindo as identidades socioculturaise profissionais, as classes e grupos sociais. 
No sul do Brasil, a implantação da agricultura familiar, a partir da primeira metade do século XIX, já sob o referencial moderno, consagra os colonos imigrantes europeus que trazem incorporada a centralidade ética do trabalho, sem, contudo ainda estarem coagidos pelo tempo e pela competitividade produtivista, pois não tinham acesso às tecnologias do progresso. Na região das colônias, reverteu-se uma tradição milenar, através da imposição do trabalho produtivo como referência valorativa de moderno. A lógica da produtividade (relação ideal entre trabalho-tecnologia-produção mensurada pelo tempo) desestruturou os saberes experimentais acumulados, e seus efeitos foram profundos, indeléveis e diferenciados sobre as diversas classes e/ou grupos sociais específicos. Redefiniu identidades profissionais e socioculturais.

O chamado progresso técnico (saber fazer humano) na agricultura brasileira a partir da década de 1950 e, sobretudo, na década de 1970, através do Pacote Tecnológico (Aguiar, 1986), impôs esse novo padrão de desenvolvimento. Os insumos, as máquinas e os equipamentos foram projetados visando produtividade e lucro a qualquer preço. 0 processo seletivo deste modelo excluiu, nas áreas onde se implantou, os agricultores, na sua grande maioria familiares, que não quiseram ou não tiveram as condições de responder positivamente.

Nessa região, a combinação entre agricultura diversificada, pecuária e agroindústrias foi, e continua sendo, a estratégia dinamizadora do desenvolvimento rural. Desenvolvimento que teve como pressuposto a sua sustentabilidade econômica, social e institucional. Esta última fundada nas cooperativas, associações e outras formas de cooperação organizada. Porém as dimensões cultural, de políticas setoriais e, principalmente, a ambiental são credoras de respeito, de pesquisas e de tecnologias apropriadas.

N esse contexto, duas tendências simultâneas, porém distintas e por vezes conflitantes, disputam as demandas dos agricultores no que se refere às pesquisas e às tecnologias que impulsionem as transformações na agricultura. 
Uma, busca de forma crescente circunscrever a produção agropecuária como segmento especializado, intensivamente tecnificada e altamente dependente (de insumos, crédito, mão de obra, mercado, conhecimentos técnicos, etc.), também conhecida como moderna convencional e é demandante de conhecimentos e de competências profissionais específicas, especializadas, cuja competitividade está diretamente vinculada à sustentabilidade econômica garantida pela produtividade. A disputa por recursos e por políticas específicas junto ao Estado é feita através de vias institucionais e do poder político constituído.

A outra, busca a redefinição de um modelo tecnológico, cuja competitividade garanta as condições de reprodutibilidade sustentável sociocultural, econômica e ambiental, no tempo e no espaço, cuja autonomia se assenta na interação, através de redes organizativas dos sistemas produtivos e dos produtorese através de políticas de desenvolvimento. Nesse modelo, a qualidade (do trabalho, do produto, do ambiente, da ocupação do espaço, etc.) é prioritária, demandante de conhecimentos e de competências profissionais diversificados e abrangentes. A disputa por recursos e por políticas específicas se dá principalmente através das lutas e mobilizações sociais, que desenvolvem consciência e práticas coletivas de planejamento como processo assumido pelas sociedades locais e/ou regionais.

Para uma e para outra, o Estado desempenha papel central, pois é a principal fonte de recursose o gerador de políticas que podem garantir seu sucesso. As profundas transformações, fundadasem uma nova racionalidade política e econômica, prevêem a redução das atribuições do Estado (retirando-Ihe seu caráter de promotor do desenvolvimento) e o aumento de poder dos agentes econômicos privados, pela liberalização dos mercados e desregulação das atividades econômicase de serviços. 0 Estado resguarda a função disciplinadora de alguns serviçose da formulação de políticas. Nesse caso, observa-se que o Estado brasileiro não tem desempenhado essas duas funções, ou seja, disciplinadora e formuladora de políticas, que 
dêem garantia de que as transformações e a tendência monopolizadora não desestruturem uma tradição de sustentabilidade do setor.

A tecnologia, tal qual entendemos hoje, é recente, simultânea à ciência moderna. mas só tomou corpo com a Revolução Industrial, quando se percebeu que tudo o que era construído pelos homens, podia sê-lo segundo os princípios das ciências (Vargas, 1985, p. 14).

A par da expansão da agricultura moderna convencional, cuja produtividade em alguns produtos se aproxima dos padrões mais elevados do mundo ${ }^{4}$, e do avanço de modelos chamados sustentáveis, subsistem regiões e/ ou segmentos de produtores, especialmente latifundiários tradicionais e familiares de subsistência, sem acesso às inovações tecnológicas, mantendose com baixa produtividade e, em geral, baixa qualidade, portanto, pouco ou nada competitivos, pois participam marginalmente do abastecimento da sociedade, ou seja, sem vínculos estáveis com os mercados. Para esses, a reprodutibilidade em padrões adequadose sustentáveis, é imprescindível à formulação de políticas públicas específicas que englobem: financiamento acessível (subsidiado) para a produção agrícola e para infraestrutura, a realização de pesquisas e o desenvolvimento de tecnologias específicas ${ }^{5}$, a qualificação de recursos humanos, a assistência técnica e extensão rural bem como a implantação de agroindústrias adequadas. 0 Conselho Nacional de Desenvolvimento Científico e Tecnológico - CNPq, somente neste ano de 2001 fez chamada para projetos em C\&T para agricultura familiar, considerando a importância da contribuição da Ciência e Tecnologia para a promoção competitiva da agricultura familiar (Edital CNPq, agosto 2001), convidou para apresentação de projetos instituições que atuam no segmento da agricultura familiar. Segundo aquele órgão, a iniciativa atende estratégia do Go-

40 arroz irrigado (RS) tem produtividade acima de $5.000 \mathrm{~kg} / \mathrm{ha}$ a mais elevada do mundo; milho e soja em algumas regiões do país é semelhante à dos Estados U nidos; aves e suínos competem em produtividade com a França. São alguns exemplos. 50 Programa do Governo estadual do Rio Grande do Sul, conhecido como RS-Rural, cujo público são os agricultores familiares de baixa renda, está financiando algumas pesquisas de diagnóstico e de desenvolvimento tecnológico para este segmento social. Alguns aspectos dessas alternativas para agricultores tradicionais de subsistência estão apontados em Gehlen, I. 1998. 
verno Federal, do Plano Plurianual 2000/2003, buscando contribuir com o suporte científico e tecnológico para a valorização do pequeno produtor rural com vistas ao desenvolvimento local integrado (idem). Até então, a pesquisa e o desenvolvimento tecnológico com apoio desse órgão voltado para a agricultura familiar e para reforma agrária, dependiam das vontades dos demandantes individuais ou agrupados.

\section{Conceitos e reconceitos: competitividade e sustentabilidade}

0 processo de (re)elaboração de conceitos pelos produtores como reação aos impactos sociais das transformações tecnológicas inclui de forma aparentemente inovadora o conceito de competitividade, incorporando as dimensões de qualidade e de produtividade. Essas duas dimensões são as que mais incidem atualmente sobre a agropecuária e possuem forte interface com as políticas normativas e de financiamento para o setor, redefinindo a reorganização do trabalho e influenciando as escolhas tecnológicas e de produtos a serem realizados, induzindo uma necessária (re)profissionalização dos agricultores familiares e a requalificação dos trabalhadores assalariados.

Para compreender este processo, é necessário analisar a noção de competitividade, cujas raízes se sustentam na experiência histórica, principalmente das cadeias agroindustriais, e na contribuição coletiva de pensadores. Cabe, portanto, analisar os impactos que a noção mesma de competitividade, com seus diferentes enfoques, que correspondem a diferentes racionalidades dos sistemas produtivos e de relações de trabalho, tem sobre os produtores agropecuários. A concepção de produtividade sob a racionalidade de produtor moderno está sendo imposta pelas agroindústrias, por cooperativas, por associações e por políticas públicas (caso, por exemplo, da nova legislação 
brasileira sobre qualidade do leite) de forma imperativa para os produtores como se fosse um consenso sobre competitividade.

A competitividade, calcada sobre as práticas dos produtorese das instituições estatais e privadas, não pode deixar de considerar que as relações entre os agricultores e essas instituições produtoras e difusoras da noção de competitividade geram impactos, pela diferenciação e reestratificação social entre os agricultores, consolidando unse excluindo outros.

O caso do leite é ilustrativo desta situação de mudanças tecnológicas com impactos sociais. Na relação com outros países, a produção brasileira de leite apresenta-se como sendo de baixa produtividade; apenas alguns países, Rússia e Índia entre eles, têm performance inferior à brasileira. Por isso, nos anos recentes, verificam-se mudanças estruturais neste segmento produtivo. A mesma disputa de tendências acima referida, verifica-se claramente nesse processo. A permanência significativa de produtores considerados de baixa produtividade, inferior a $50 \mathrm{l} /$ dia por produtor ${ }^{6}$, em muitos casos de tipo tradicional, com produtividade inferior a $5 \mathrm{l} /$ dia vaca) constituise num desafio, pois representa potencialidade de expansão da produção e sustentabilidade pela preservação da ampla base social, mas também representa potencial de exclusão do sistema resultado do processo de seleção.

A tabela 1 mostra a intensidade e a direção das transformações no segmento leite no Brasil. 0 consumo cresce em índices elevados no Brasil, principalmente 0 leite beneficiado com a tecnologia UHT (longa vida). 0 mercado informal cresce mais rápido, passando, no período considerado de $34 \%$ para 44\%. Segundo dirigentes de cooperativas e de grandes laticínios, a expansão da demanda continuará nos próximos anos, até para produtos diferenciados, tipo ecológicos.

6 Dados do Censo Agropecuário do IBGE 1995 e da Associação Gaúcha de Laticínios apontam que 87,7 \% produzem menos de 50l/dia no Brasil, sendo que, no Sul, são $69,10 \%$, no N ordeste $95,9 \%$ e no Centro O este $72,6 \%$. Apenas $2,69 \%$ de produtores entregam mais de $200 \mathrm{I} / \mathrm{dia}$, no entanto estes produzem $19,76 \%$ do leite, no Brasil. 
Tabela 1: M ercado brasileiro de leite e derivados em milhões de litros fluidos

\begin{tabular}{|c|c|c|c|}
\hline Situação & 1990 & 1998 & Variação* \\
\hline Consumo total & 15.393 & 22.307 & $36 \%$ \\
\hline $\begin{array}{l}\text { Consumo per capita } \\
\text { (l/hab./ano) }\end{array}$ & 106 & 136 & $28 \%$ \\
\hline Produção & 14.484 & 20.087 & $29 \%$ \\
\hline Formal & 9.609 & 11.345 & $16 \%$ \\
\hline Pasteurizado & 4.030 & 2.745 & $-27 \%$ \\
\hline Longa Vida (UHT) & 184 & 3.100 & $895 \%$ \\
\hline Derivados & 5.395 & 5.500 & $9 \%$ \\
\hline Informal & 4.875 & 8.472 & $52 \%$ \\
\hline Importações & 909 & 2.220 & $146 \%$ \\
\hline Longa Vida / Fluido & $4 \%$ & $53 \%$ & - \\
\hline $\begin{array}{l}\text { Importação / } \\
\text { M ercado Formal }\end{array}$ & $9 \%$ & $16 \%$ & - \\
\hline $\begin{array}{l}\text { Tamanho do } \\
\text { mercado informal }\end{array}$ & $34 \%$ & $44 \%$ & - \\
\hline
\end{tabular}

\section{* Triênio 1996/98 sobre o triênio 1990/92.}

Fonte: DECEX/MAARA/LEITE BRASIL/SUNAB/ABLV/ABIQ apud Révillion, 2000, p. 78.

A busca ou aprofundamento de um olhar crítico sobre o rural complexo, crescentemente diferenciado: produtor de mercadorias cada vez mais profissionalizado, produtor tradicional de subsistência cada vez menos integrado, ou produtor combinando as duas racionalidades, situa-se num quadro de análise que considere, ao menos, algumas tendências "globalizantes" que afetam fortemente a agropecuária no sentido de definir seu perfil para as próximas décadas.

A primeira refere-se às mudanças decorrentes do processo acima descrito em relação ao conceito e à relação trabalho - tempo, que desestruturam a tradição dos agricultores familiares de forma diferenciada. Para os que já tinham incorporado a centralidade ética do trabalho, a 
tecnificação induz o tempo como controle e a produtividade como objetivo. Para as categorias que não subjetivaram a centralidade ética do trabaIho, os caboclos por exemplo, impõe-se primeiramente a necessidade de reconversão valorativa para a ética moderna do trabalho e após, a submissão ao controle do tempo / produtividade, evidentemente caso a opção seja de se reestruturarem como produtores modernos competitivos. N esse novo contexto, a referência de identidade profissional idealizada é a do empresário, para quem o "tempo vale ouro". Tais mudanças são direcionadas por um discurso e por exemplos que consagram a eficiência competitiva do produtor moderno, estreitamente vinculada à racionalidade do mercado, apresentado como um ente onipresente, porém inatingível pelas pressões individuais ou de organizações locais.

A segunda tendência é a formação de consenso em torno de tecnologias padronizadoras : de insumos, de variedade, de qualidade, de produtividade. Consenso que, ao mesmo tempo em que anula ou desqualifica o tradicional, possibilita espaços para recriar formas de afirmação das diferenças positivas, do capital social enquanto locus do desenvolvimento .

A terceira é a crescente importância da genética, da química e da informação para a agropecuária, de forma que esta já se alinha com os procedimentos industriais para produzir. Junta-se a estas tensões o fato de que 0 modelo produtivista (moderno-convencional) está em crise causada pelos seus impactos ecológicos e sociais e pelo seu fracasso como solução global para a fome. A produção ecológica, acessível de forma crescente aos pequenosprodutores, tende a subverter a lógica imposta pelas grandes agroindústrias aos produtores familiares, pois tende a constituir focos de resistência a essa lógica, dispondo de um formato tecnológico alternativo, além de o seu produto ser diferenciado no sentido de prezar tanto pela preservação da identidade sociocultural do produtor rural quanto pela qualidade, devido ao fato de ser um produto ecológico, logo, saudável ao consumidor. 
A quarta corresponde ao progressivo atrelamento da produção agropecuária às Cadeias Agroindustriais. Esse atrelamento se faz acompanhar de processos seletivos de inclusão / exclusão dos agricultores.

Por último, a crescente valorização do consumidor, como parte interessada e interveniente na definição de conceitos de qualidade do alimento, do ar, da água, do uso do espaço e de estética para a agricultura, e como interveniente .

Essas tendências apontam para perspectivas globalizantes que integram o específico (particular) com o geral (universal), possibilitam, contraditoriamente, valorizar os modos de vida diferentes, os sistemas produtivos construídos historicamente, as identidades marginalizadas pela modernidade e nos imergem na raiz de contradições da brasilidade em formação. Contradições estas que, em plena "globalização", sustentam paradigmas analíticos que os excluem de seus objetos e modelos de desenvolvimento, que os estigmatizam ${ }^{7}$, responsabilizando-os pelo atraso e pela pobreza, imputando-lhes culpa pela própria exclusão.

\section{Competitividade e sustentabilidade, desafios da pesquisa e das tecnologias}

A força da noção de competitividade - como padrão a ser atingido está relacionada às transformações econômicas na estrutura produtiva. A centralidade da produtividade como critério de competitividade se expande e se consolida na agropecuária brasileira, a partir da primeira metade da década de 1970 (Aguiar, 1986). 0 fato mais significativo foi a criação da Empresa Brasileira de Pesquisa Agropecuária (EM BRAPA) em 1973. Esta empresa Estatal produziu inovações, especialmente em bioquímica, técni-

70 estigma visa tornar o processo social excludente e aparentar as diferenças sociais como naturais, invertendo a percepção do real. Responsabiliza os estigmatizados pela sua exclusão, como resultado da incapacidade de adaptação ao meio ou ao trabalho (no caso dos caboclos). Visa, enfim, evitar a negação do modelo social que lhesé estruturalmente excludente. Cf Goffman, Erving, Estigma: notas sobre a manipulação da identidade deteriorada. Rio de Janeiro, Guanabara Koogan, 1988 (original 1963). 
cas de manejo de solo, adaptações para as condições brasileiras. No entanto a atividade da EM BRAPA encontra limites nos recursos de pesquisa. Na média, o Brasil investiu em Ciência e Tecnologia, na década de 1990, apenas $0,4 \%$ do PIB (em outros países considerados mais desenvolvidos, esses investimentos são entre 2 e $3 \%$ do PIB). Nessa empresa, as biotecnologias, a informatização e os paradigmas ambientalistas, orientam as suas principais linhas de estudo nestes últimos anos.

Q uadro 1: Sistema institucional de Ciência e Tecnologia Agropecuária no Brasil

\begin{tabular}{|l|l|}
\hline Federais & $\begin{array}{l}\text { EMBRAPA, Universidades, } \\
\text { M inistérios. }\end{array}$ \\
\hline Estaduais & $\begin{array}{l}\text { Empresas Estatais, } \\
\text { Secretarias estaduais e } \\
\text { municipais, EM ATER }\end{array}$ \\
\hline Municipais & $\begin{array}{l}\text { Escolas técnicas, centros } \\
\text { experimentais }\end{array}$ \\
\hline "Públicas" - não-estatais & O NGs, Fundações \\
\hline "Privadas" sociais & $\begin{array}{l}\text { Cooperativas: } \\
\text { (FECO TRIGO), } \\
\text { Universidades (Faculdades) }\end{array}$ \\
\hline Privadas & $\begin{array}{l}\text { (Agro)Indústrias, } \\
\text { Universidades (Faculdades), } \\
\text { M icroempresas de pesquisa, } \\
\text { de desenvolvimento } \\
\text { tecnológico }\end{array}$ \\
\hline
\end{tabular}

As demais instituições do sistema de pesquisa de extensão agropecuária, carecem ainda mais de recursos de pesquisa, muitas restringindo-se a testes de impactos e avaliações de eficiência tecnológicas, sem geração de saber. 
De modo geral, a pesquisa em ciência e em tecnologia agropecuária no Brasil é predominantemente pública, e seus resultados, portanto, constituem um bem de uso público, mesmo que assim não o tenham sido sempre em todos os setores. Neste sentido, beneficia a sociedade em geral, mas nem sempre garante retorno financeiro para as entidades pesquisadoras. Daí a necessidade de mantê-la publica e subsidiada.

No modelo em que o Estado, aos poucos, abandona seu caráter desenvolvimentista e/ou intervencionista, abre espaço para a subordinação ainda maior no que se refere à pesquisa e às tecnologias, às pressões de organismosinternacionais (FMI, Banco M undial, multinacionais de insumos, de sementes e de máquinas agrícolas). Na década de 90, a continuidade desse processo se opera através da internacionalização de empresas que se instalam no país ou compram agroindústrias brasileiras. A Italiana Parmalat adquiriu 14 empresas brasileiras de industrialização de leite no período 1990 e $1998^{8}$, tornando-se a maior empresa do setor no Brasil.

A implementação de políticas de pesquisa e de difusão tecnológicas que objetivam consolidar este novo modelo estão associadas a políticas que objetivam administrar a crescente dependência financeira externa. o u seja, facilitar o ingresso de tecnologias de empresas multinacionais, estimular as iniciativas privadas em C\&TA e facilitar as exportações primárias, que são superavitárias. A competitividade, num sentido geral, é a meta, direcionando o processo chamado de reestruturação produtiva que também atinge as atividades agropecuárias. As empresas são pressionadas, à abertura ao mercado internacional e a se adequarem aos padrões competitividade (produtividade e qualidade), segundo determinantes do mercado globalizado. A não-adequação às exigências desse mercado põe em risco a sobrevivência das empresas. Portanto, a competitividade está no centro da redefinição produtiva e incorporou outros atributos, além da eficiência produtiva e preço, tais como a qualidade dos produtos, do processo produtivo e do meio ambiente. Incorpora também a diversidade de produtos e a qualificação dos trabalhadores.

8 Conferir Boletim do Deser, no 117. 
As agroindústrias constroem suas estratégias de acumulação, a montante da cadeia produtiva, através da transferência dos conflitos com os produtores (por preço, por tecnologia, por critérios de qualidade, etc.) para o campo das relações interpessoais destes com os técnicos que executam as políticas das agroindústrias ou políticas desenvolvimentistas, ou seja, para as instituições geradorase difusoras de saber e de tecnologias. A jusante, articulam-se com os distribuidores e com os consumidores (através da publicidade, por exemplo) justificando os seus elevados preços pelos custos de produção da matéria e pelos impostos. Através deste recurso-subterfúgio impõem suas exigências tecnológicas (seu pacote tecnológico) e seu conceito de competitividade baseado na produtividade e na qualidade, que se equivale ao cumprimento de norma legais de sanidade e de procedimentos no sistema produtivo. Esta ardilosa manipulação do poder do consumidor facilita o repasse de novas tecnologias: variedades ou raças, insumos, rotinas e equipamentos. Esta artimanha enfraquece o poder de barganha do produtor, pois o consumidor possui identidade abstrata, substituto do conceito de mercado. Nessa relação a jusante, o distribuidor assume o papel de representar os interesses dos consumidores, que tendem a afirmar a sociedade de consumo pelo controle e fiscalização.

U ma outra dimensão estratégica desta ambigüidade é a mistificação do modelo tecnológico, no sentido de impor aos agricultores a tecnologia como a solução de seus problemas, como uma alternativa quase mágica e única, no sentido de "ou adota ou será excluído". Ela é apresentada como salvacionista, que resgataria o produtor da pobreza, situação em que se encontra a maioria das famílias agricultoras familiares de amplas regiões do país. Seu pretenso efeito é a sujeição ao modelo, necessário para a cumulação, a desqualificação do tradicional e a desmobilização política.

A obtenção de competitividade sofre influência de vários fatores e agentes que definem os padrões de qualidade e produtividade. Entre os fatores internos à cadeia agroindustrial, no caso do produto leite, que definem esses padrões estão os equipamentos como ordenhadeiras resfriadores e instala- 
ções específicas; os alimentos como ração concentrada; a assistência técnica veterinária e agronômica; o transporte; os medicamentos, etc. Este conjunto de fatores, impõe-se progressivamente sobre os produtores, construindo ideologicamente a idéia de que somente algumas unidades produtivas apresentam as condições competitivas, ou mérito para continuarem como tal. As demais estão permanentemente ameaçadas de serem excluídas do sistema. As práticas alternativas, no entanto, podem crescer e beneficiar produtores que consigam estabelecer acordos formais ou informais de confiança com os consumidores, no sentido de estes privilegiarem seus produtos.

Esta guilhotina que ameaça parte dos produtores agropecuários do Brasil tem como antídoto a crescente organização em cooperativas, em sindicatose em associações, por sua vez crescentemente articuladas, em rede. Elas capitalizam as pressões através de lutas sociais e se utilizam de ações de impactosna opinião pública para publicitar suas condições de vida e de explorados e suas demandas, com vistas a conquistar a adesão do consumidor. Ardilam formas específicas como caminhadas pelas estradas, acampamentos em frente às agroindústrias, aos bancos, etc., reivindicando preços, políticas de apoio, recusando normas restritivas a atividades de transformação, entre outras.

A imposição de novas tecnologias e técnicas pelas grandes agroindústrias, visando à maximização da produção e um padrão determinado de apresentação e de qualidade do produto, tem sido reconhecida como um fator agravante da situação desses produtores. 0 alto custo de produção conciliado à baixa renda obtida nos seus negócios obrigará muitos a optarem por outras atividades econômicas.

\section{Políticas públicas, tecnologia e competitividade agropecuária}

Este choque entre paradigmas, entre concepções de desenvolvimento e modernidade, altera a própria noção de qualidade, pois, no caso ecológico (ver Altieri, 1989) inclui a relação indivíduo - meio ambiente, numa 
nova correlação entre sujeito e meio. No modelo convencional ainda difundido pela grande maioria das agroindústrias, consagra uma relação com o meio ambiente, marcada pela sua insustentabilidade ecológica.

A dinâmica seletiva que ameaça os agentes que constituem o elo responsável pela produção de matéria prima na cadeia produtiva pode ser estrategicamente alterada por alternativas que corrijam e, em alguns casos sejam antagônicas à lógica dominante empreendida pelas políticas e pelas empresas dos complexos agroindustriais. Entre os fatores decisivos para as mudanças em curso na estrutura, estão as transformações que afetam o Estado em si mesmo. Este, um agente exógeno à cadeia produtiva, mas com um profundo poder de determinação sobre ela.

No final da década passada, iniciou-se um processo de relativa perda de competitividade do setor agropecuário brasileiro em relação a outros países, em razão da diminuição de recursos direcionados ao financiamento da produção e também em razão da crescente queda de investimento em pesquisa e desenvolvimento tecnológico para o setor. 0 setor não está respondendo adequadamente à expectativa governamental de que 0 agronegócio aumente rapidamente suas exportações, em conseqüência deste quadro de políticas públicas para o setor.

Conforme já referido acima, há programas que afetam diretamente a produtividade e a competitividade dos produtores agropecuários, tanto federais, quanto estaduais e, em muitos casos, municipais. Esses recursos financiam o sistema público de geração e de difusão de tecnologia e, embora timidamente, também a produção de conhecimentos. Há programas que investem em mecanização da atividade agropecuária e na melhora ou defesa sanitária. A tabela abaixo mostra gastos com esses programas. Verifica-se uma redução do gastos públicos entre 1992 e 1995, retornando a seu patamar a partir de 1996. Pelo crescimento do item referente à administração (4.07 da tabela abaixo), constatam-se transferências a instituições privadas, 
pessoal, custeio, investimentose inversões financeiras. 0 crescimento tem a ver também com melhoria salarial do funcionários da EM BRAPA.

Em ciência e tecnologia (itens 4.10 a 4.40), verificou-se um aumento entre 1995 e 1996, porém diminuem em 1997, ficando em cerca de 500 milhões de dólares, inferior a cinco anos antes, quando, em 1991, atingiu 1 bilhão de dólares.

As despesas com programas de geração e difusão de tecnologia agropecuária (4.10 a 4.18 da tabela) revelam que, no final da década de oitenta, eram maiores os recursos disponibilizados. N os anos 90 , o financiamento da agricultura manteve valores bem abaixo daqueles concedidos durante a década de 70, bem como dos valores observados nos anos 80 (Magalhães, 1988 p. 201). Essa diminuição de investimentos para o crescimento da produtividade pode inviabilizar pesquisas em andamento e trazer conseqüências negativas para a economia nacional a médio prazo.

O s dad os sobre o financiamento das atividades, os quais vão afetar a produtividade do setor agropecuário no longo prazo, não se observa uma indicação de incremento de recursos na área de pesquisa e difusão de tecnologia. Os gastos que apresentam crescimento são aqueles ligadosa defesa sanitária vegetal e animal, para isto deve ter contribuído a necessidade da produção nacional adequar-se as normas internacionais, ou mesmo regionais, como as negociadas no âmbito do M ercosul (Vila Verde, 1997).

O s gastos com pesquisa na agropecuária permanecem estacionários e utilizados basicamente para o desenvolvimento tecnológico, portanto, não indicam preocupação com aumento das condições competitivas do setor primário. 
Sociologias, Porto Alegre, ano 3, no 6, jul/dez 2001, p. 70-93

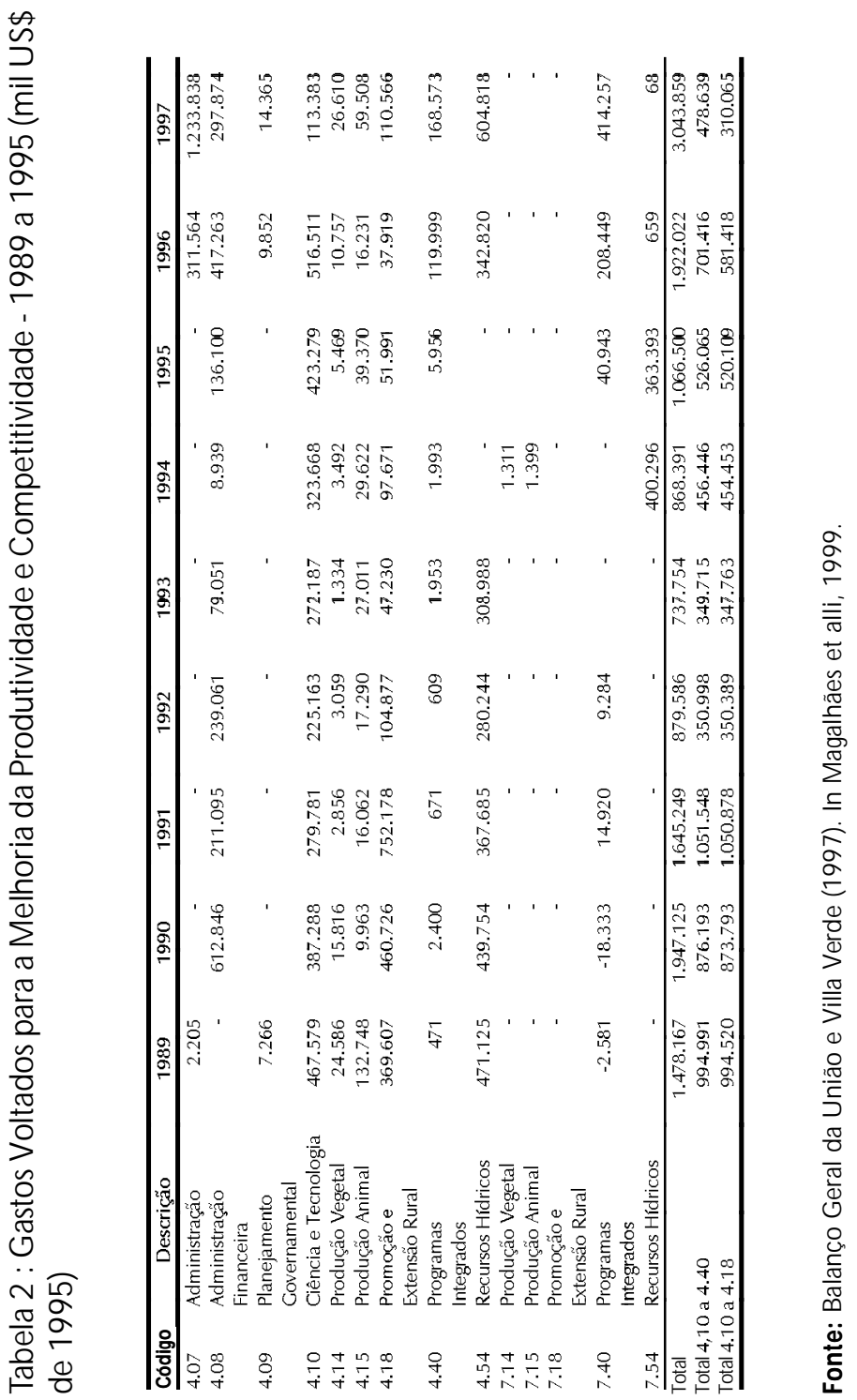


A contraposição do conceito de produtividade ao de reprodutibilidade, ou sustentabilidade social como parte do conceito de competitividade, parece ser um embate eficaz para a produção de uma cultura de resistência, especialmente de agricultores familiares. Porém demandante de tecnologias apropriadas. Algumas iniciativas objetivando reconceituar a competitividade à luz da sustentabilidade em seu sentido amplo, foram levantadas pelo autor em recente pesquisa sobre produtores familiares de leite no Rio Grande do Sul (Gehlen, 2000). Tais iniciativas, que buscam interagir conceitos "teóricos" com experiências práticas e técnicas, desenvolvem-se principalmente em ambientes de cooperativas, de associações de produtores e entre técnicos e lideranças sindicais, opondo-se a culturas atualmente já hegemônicas, difundidas pelas agroindústrias que dominam as cadeias produtivas. 0 estudo dessas iniciativas possibilitariam analisar melhor o conflito entre a racionalidade competitiva das agroindústrias que priorizam a produtividade, e a racionalidade reprodutiva dos agricultores familiares que priorizam a reprodução e a sustentabilidade social, cultural, econômica e ambiental, numa tentativa de estancamento do processo de exclusão que os ameaça. Este debate, embora referenciado num empírico local, possui universalidade em seu conteúdo teórico.

Alguns exemplos das práticas tecnológicas em implantação, permitem auscultar as tendências deste processo e possibilitam ganhos competitivos necessários para seu desenvolvimento sustentável.

Atribuir centralidade estratégica a um ou dois produtos, reestruturando racionalmente - atendendo requisitos tecnológicos de sustentabilidade em suas diversas dimensões e planejamento do uso do espaço e das potencialidade locais -, o sistema produtivo nesta perspectiva e remanejar 
responsabilidades da força de trabalho familiar, como por exemplo, passar a atividade leiteira para alguém qualificado, deixando de ser atividade secundária ou complementar aos serviços domésticos.

M elhorar ganhos de produtividade de forma evolutiva, sem estabelecer patamares rígidos e valorizando ao máximo os recursos existentes na propriedade, tais como a genética, sementes, vegetação, clima, água, fertilidade, etc. No caso da alimentação animal, priorizar o pasto (em que o próprio animal coleta) e implantar sistemas rotativos e variedades que melhor se adaptem, diminuindo o uso de alimentos fornecidos (ração e outros) a um patamar atualmente quantificado em cerca de $40 \%$. 0 modelo proposto pelas agroind ústrias monopolistas (moderno convencional) recomenda, atualmente, um patamar em torno de $60 \%$ de alimentos fornecidos.

Construir o capital social da solidariedade racionalmente estruturada, através de alternativas de cooperação, como organizações profissionais específicas para ascender a novas tecnologias que potencializem o sistema produtivo, como, por exemplo, compra de equipamentos em comum, troca de genéticas, de sementes, de mudas de gramíneas para pastagem; compartilhamento de recursos hídricos, etc. Essas mesmas associações/ cooperativas podem facilitar e potencializar a assistência técnica, a capacitação continuada, compartilhando experiências bem sucedidas e 0 acesso a informações.

Complementar a difusão através de programas de qualificação dos produtores, especialmente os jovens, como escolas técnicas, cursos de duração curta, seminários, palestras, dias de campo, audiovisuais, rádio, etc. Desenvolver, através da qualificação, uma cultura de cooperação segundo a lógica de cadeia produtiva, estabelecendo confiança e solidariedade entre todos os segmentos. Isso facilitará a compreensão e o acesso ao mercado e possibilitará ganho de confiança do consumidor, viabilizando a difusão de marcas e de certificações de origem. 
Concluindo estas reflexões gerais sobre pesquisa, tecnologia e competitividade na agropecuária brasileira, pode-se inferir claramente que o aumento competitivo através do crescimento da produtividade foi expressivo nas décadas de 1970 e 1980. Entretanto, recentemente, a produtividade da terra e do trabalho indicam redução (Gasques e Conceição, 1997), mesmo em cadeias tradicionais que apresentavam vantagens comparativas como soja, café e suco de laranja, nas quais, Magalhães e outros (1999) apontam diminuição competitiva. A diminuição de gastos com os programas de pesquisa e desenvolvimento de tecnologia agrícola apresentam já resultados limitadores da capacidade do setor para incrementar sua competitividade internacional. Esta instabilidade, com tendência a diminuir os investimentos públicos em pesquisa cientifica, não compensados pelo privado, comprometem a competitividade futura do setor e revelam a fundamental importância das instituições públicas de ciência e de tecnologia para a agropecuária. Também contribuem para legitimar os que buscam alternativas, como o esforço que alguns segmentos, especialmente de agricultores familiares, estão realizando para reconstruir o conceito e as tecnologias de competitividade vinculados à sustentabilidade.

\section{Referências bibliográficas}

ABRAM O VAY, Ricardo. Paradigmas do capitalismo agrário em questão. São Paulo: Hucitec, 1992.

AGUIAR, Ronaldo Conde de. Abrindo o pacote tecnológico. São Paulo: Polis/CN Pq, 1986.

ALTIERI, Miguel A. As bases científicas da agricultura alternativa. Rio de Janeiro: PTA/ FASE, 1989. 
BOU LIN, Jean-Yves; GILBERT, Cette; TADDÉl, Dominique (O rgs). Le temps de travail. Paris: Syros, 1993.

BRANDÃO, Carlos R. e REIS, Samuel A. A tecnologia alternativa, educação e saber. Salvador: DEPED/CENDRO, 1982 (mimeo).

DAH REN D O RF, Ralf. O conflito social moderno um ensaio sobre a política da liberdade. Rio de Janeiro: Zahar / EDUSP, 1992.

DESER. Boletim do Deser. n 117, Curitiba, DESER, jan 2001, p. 5 a 14.

EM BRAPA. Pesquisa para agricultura auto-sustentável: perspectiva de política e organização na EM BRAPA. Braślia: EM BRAPA, 1994.

FERRARIS, Pino. Desafio tecnológico e inovação social: sistema econômico, condições de vida e de trabalho. Petrópolis: Vozes/IBASE, 1990.

FIGUEIRED O, Vilma. Produção social da tecnologia. São Paulo: EPU, 1989.

GASQ UES, José G. e CONCEIÇÃO, Júnia C. P. R.. Crescimento e Produtividade da Agricultura Brasileira. In: Preços Agrícolas, v. 11, n. 131, 1997.

GEHLEN, Ivaldo (coord.) et alli. O s anos noventa e o "novo rural": transformações tecnológicas e impactos sobre o desenvolvimento rural no contexto da agricultura familiar no Rio Grande do Sul. Porto Alegre, UFRGS/IFCH, 2000 (Relatório de Pesquisa).

GEHLEN, Ivaldo. Agricultura Familiar de Subsistência e Comercial: identidade cabocla e inclusão social. In: Ferreira, A. D. D., Brandenburg, Álfio (orgs). Para pensar outra agricultura. Curitiba, UFPR, 1998, p.51-70.

GEHLEN, Ivaldo; MÉLO, José Luiz Bica de. A dinâmica da agricultura no Sul do Brasil: realidade e perspectivas nos anos noventa. São Paulo, SEADE, São Paulo em Perspectiva, vol. 11 no. 2, 1997, p. 99 - 108. 
GOODMAN, David; SORJ, Bernardo; WILKINSON, John. Da lavoura às biotecnologias. Agricultura e indústria no sistema internacional. Rio de Janeiro, Campus, 1990.

GRAZIANO DA SILVA, José. Progresso técnico e relações de trabalho na agricultura. São Paulo: Hucitec, 1981.

GRAZIANO DA SILVA, José. O progresso técnico na Agricultura. Campinas, UNICAMP, 1988 (mimeo).

MAGALHÃES, Luís Carlos, TOMICH, Frederico A., SILVEIRA, Fernando Gaiger. Competitividade e políticas públicas para o agronegócio brasileiro: desafios e perspectivas. Indicadores Econômicos FEE, Porto Alegre, v.6, no4, mar. 1999, p. 196- 217.

M AIA, Kátia Drager. Agenda de D esenvolvimento Sustentável. In: PNUD- Instituto de Política. Agenda de desenvolvimento humano e sustentável para o Brasil do século XXI. Brasília, 2000, p. 353 a 378.

MARTINE, George; GARCIA, Ronaldo Coutinho. Os impactos sociais da modernização agrícola. São Paulo, Caetés, 1987.

PNU D-Programa das Nações Unidas para o Desenvolvimento. Relatório de Desenvolvimento Humano. Brasília, 1999.

PO RTO, Maria Stela Grossi (org.). Politizando a tecnologia no campo brasileiro: dimensões e olhares. Editora Relume - Dumará, Rio de Janeiro, 1997.

RÉVILLION, Jean Philippe. Estudo das variáveis relevantes na adoção do processamento UHT nas agroindústrias de laticínios do Estado do Rio Grande do Sul. Porto Alegre: UFRGS/PPG em Agronegócios, 2000 (Dissertação).

SCHNEIDER, João Elmo. Patentes em biotecnologia: estímulo ou obstáculo à produção do conhecimento e inovações? In: Ciência Hoje. 15 (88), março, 1993, pp $35-40$. 
VARGAS, Milton. Ciência, Técnica e Realidade. In: Revista da USP (Universidade de São Paulo). São Paulo: USP, no 14, jun / ago 1992, pp 96 - 103.

VARGAS, Milton. M etodologia da pesquisa tecnológica. Porto alegre: Globo, 1985.

VILLA VERDE, Carlos M. Gastos Governamentais Voltados para a M elhoria da Produtividade e Competitividade da Agricultura. Texto para Discussão n. 531, IPEA. Brasília: dezembro/1997.

WILKINSO N, John. O Estado, a agroindústria e a pequena produção. Bahia: ditora Hucitec, 1986.

\section{Resumo}

As transformações estruturais que ocorrem na agropecuária brasileira estão em interface com o desenvolvimento científico e tecnológico voltados para o setor. A consolidação de um novo referencial em Ciência e Tecnologia Agropecuária, apresenta-se como possibilidade de reconstruir um consenso pela noção de competitividade, a qual reintroduz a centralidade positiva do trabalho, porém vinculada à responsabilidade e eficiência individual, perpetuando e acentuando as diferenças pelo acesso diferenciado às oportunidades. A análise leva em conta o conflito conceitual entre a racionalidade competitiva das agroindústrias, que priorizam a produtividade para a cumulação - recriando formas de sujeição pela desqualificação do tradicional e pela desmobilização política - e a racionalidade daqueles agricultores que, através de suas organizações, priorizam a sua reprodução social e a sustentabilidade de seu modo de produção e de vida. A contraposição do conceito de produtividade pelo de reprodutibilidade ou sustentabilidade social como parte do conceito de competitividade contribui para a produção de uma cultura de resistência, especialmente entre agricultores familiares. A instabilidade e diminuição dos investimentos públicos em pesquisa e em tecnologia, não compensados pelo privado, comprometem a competitividade futura da agropecuária brasileira.

Palavras-chave: Ciência \& tecnologia agropecuária, competitividade e tecnologia, produtividade e reprodutibilidade social, investimentos em C\&T agropecuária, racionalidade produtivista, racionalidade sustentável. 